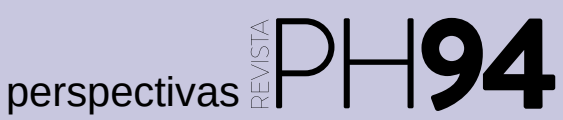

a debate El marco legal para la protección del patrimonio paleontológico. ¿Qué pasa en tu comunidad?

| coordina Eloísa Bernáldez Sánchez

\title{
El patrimonio paleontológico de mi comunidad
}

Julio Fabián Merlo | Facultad de Ciencias Sociales, Universidad Nacional de Centro de la Provincia de Buenos Aires

URL de la contribución <www.iaph.es/revistaph/index.php/revistaph/article/view/4176>

\begin{abstract}
¿Debe tener el patrimonio paleontológico un marco legal propio y específico? ¿por qué? ¿Cuál es la situación en tu comunidad o país?

Es imprescindible que cada disciplina tenga un marco legal propio y específico ya que el estudio del territorio ha sido efectuado desde diferentes disciplinas que lo han abordado desde diversos puntos de vista (geología, ecología, geografía, sociología, arquitectura, antropología, arqueología, entre otras). Tradicionalmente la geografía se ha dedicado a los estudios territoriales y la arquitectura la encargada de analizar y regular el crecimiento de los centros urbanos. En consecuencia, suelen dejarse de lado el registro de sitios arqueológicos y paleontológicos. Muchas veces es producto del desconocimiento o de no ver la importancia y la información que puede brindar un resto fósil o arqueológico ubicado en su contexto original. También existe un temor inminente a que el hallazgo de algún resto material de este tipo genere la expropiación o pérdidas económicas serias tanto de los dueños del lugar o de la empresa encargada.
\end{abstract}

Es el caso del partido de Olavarría (provincia de Buenos Aires, Argentina), el mayor centro minero del país (se extrae cal, caliza, dolomita, arcilla, arena, laja y pedregullo) y el mayor productor de cemento a nivel nacional. Esto le otorgó a la región un polo industrial de alto rendimiento económico. Por este motivo, la preocupación está en mantener este rendimiento productivo y no destinar recursos a la protección del patrimonio paleontológico ni arqueológico, que se encuentran en los estratos superiores de estos depósitos, a pesar de que la ley nacional 25.743 establece la protección de ambos registros.

En síntesis, esto genera que frente al hallazgo de algún reto fósil o arqueológico sea destruido antes de permitir el ingreso de investigadores que lo puedan resca- tar. Un ejemplo de esa situación se dio en el 2006, en una cantera de la localidad de Sierra Chica, partido de Olavarría, donde un operario encargado de realizar la extracción de los sedimentos superiores con una pala mecánica detectó la presencia de varios restos fósiles. Esta persona detuvo el trabajo y buscó contactarse con investigadores de la Facultad de Ciencias Sociales de Olavarría (UNICEN), pero el dueño de la concesión de la cantera obligó al obrero a dinamitar los hallazgos o, de lo contrario, iba a ser despedido. En otros variados casos el aporte de fósiles fue hecho de manera clandestina por operarios curiosos frente al hallazgo, pero con la condición de no revelar por ningún medio de prensa el lugar ni la identidad del rescatista. Muchos materiales de este tipo no pudieron ser dados a conocer por la comunidad en general.

\section{¿Por qué es importante la protección del patrimonio paleontológico?}

En nuestro país, los recursos materiales y técnicos que se destinan a la protección del patrimonio paleontológico o arqueológico limitan seriamente su protección. En nuestra zona (interior de la provincia de Buenos Aires), se hace necesario adoptar criterios que permitan establecer niveles de significación de los sitios paleontológicos y prioridades en base a las necesidades que presenten los mismos (ver Carta de ICOMOS de 1990, art. 6; GRENVILLE; FAIRCLOUGH, 2004-5: 2). En muchos de los casos no se cuenta con recursos económicos y personal técnico para realizar el rescate de fósiles. Mucho menos se cuenta con especialistas que realicen la tarea de difundir a la comunidad el trabajo de los paleontólogos. En períodos de sequías, quedan expuestos en las barrancas de arroyos y ríos numerosos fósiles, que son visualizados por lugareños curiosos o aficionados. Estos suelen efectuar rescates improvisados utilizando técnicas y materiales ad hoc; en muchos casos, cuentan 
a debate El marco legal para la protección del patrimonio paleontológico. ¿Qué pasa en tu comunidad?

su experiencia en medios de prensa locales que suelen presionar a los gobiernos municipales a llamar a especialistas para mejorar su recuperación, o que puedan dar datos científicamente sustentables de los hallazgos y difundir por estos medios a la comunidad la preocupación por la preservación del patrimonio local. Un punto positivo para estos mecanismos es que muchos de estos casos fueron útiles para programar un trabajo científico y didáctico complementario para abordar la enseñanza de las ciencias naturales, generando primeramente un acercamiento a la paleontología para finalmente ser volcado en un museo y ayudar a la creación de un sentimiento de pertenencia vinculado al patrimonio fósil de la región pampeana.

¿Cuál es el papel del paleontólogo o paleontóloga en los proyectos de investigación e intervención patrimonial? ¿Qué formación específica ha de tener? Un modelo de trabajo conjunto entre los investigadores y sus instituciones y la comunidad, que amplía el valor de los hallazgos y contribuye a profundizar las investigaciones y la sensibilización acerca de la importancia del patrimonio y de la cultura como un hecho de construcción colectiva, como así también de la riqueza material y simbólica del territorio pampeano. Considero que el investigador no debe tener una formación específica para difundir el patrimonio, sí incitar para contribuir a los encargados de la comunicación de este patrimonio y por ende contar con recursos económicos y de personal para hacerlo.

¿Cómo ha influido la incorporación de las nuevas tecnologías en la protección/desprotección del patrimonio paleontológico?

Los nuevos medios tecnológicos han influido satisfactoriamente en la elaboración de los mapas esenciales en el proceso moderno de caracterización del paisaje, área que se ha facilitado y enriquecido en los últimos años, gracias al uso de nuevas herramientas y tecnologías, tales como los sistemas de información geográfica, incluidos los mapas históricos digitales. Los medios de comunicación en 3D para darle animación y movimiento a los fósiles que hoy encontrarnos. En las últimas décadas el cine ha generado un interés importante en el público infantil que repercute en los familiares mayores para la protección del patrimonio paleontológico. La cara negativa de todo esto en el ámbito local es la falta de políticas para logar una correcta recuperación de los restos fósiles. En la región pampeana bonaerense se encuentran muchos huesos fosilizados, pero en mucho de los casos no se cuenta con recursos económicos, investigadores y técnicos idóneos en este punto. Contamos con una ley de protección de los patrimonios, pero en esta legislación no hay ningún ítem que determine quién debe aportar los recursos para realizarlo. Las políticas de protección del patrimonio paleontológico y arqueológico deben estar sistemáticamente integradas en las de la agricultura y la utilización, desarrollo y planificación del suelo, así como en las relativas a cultura, medio ambiente y educación. La participación activa de la población debe incluirse en la protección, recuperación y conservación de los patrimonios (paleontológicos, arqueológico, intangible, etc.). Resulta esencial lograr la accesibilidad a los conocimientos; condición necesaria para tomar cualquier decisión. La información al público es un elemento importante para conservar de manera continua el patrimonio de una comunidad.

\section{BIBLIOGRAFÍA}

- GRENVILLE, J.; FAIRCLOUGH, G. (2004-5) Characte risation. Introduction. Conservation Bulletin, 47, 2004-5, pp. 2-3

- CARTA Internacional para la Gestión del Patrimonio Arqueológico (1990) [en línea] Asamblea General del ICOMOS, Lausana, $1990<\mathrm{https}$ ://www.icomos.org/images/DOCUMENTS /Charters/arch_sp.pdf> [Consulta: 17/04/2018] 